\title{
Atypical Aging Defect: Sensory Discrimination, Viticultural Causes, and Enological Consequences. A Review
}

\author{
Volker Schneider ${ }^{1 *}$
}

\begin{abstract}
Atypical aging is an off-flavor that can occur in white wines within a period of a few weeks to one year after the first addition of sulfur dioxide postfermentation. Its sensory characterization is varied and controversial, including a premature loss of varietal aroma combined with an increase in off-flavors that comprise various attributes such as mothballs, furniture varnish, acacia blossom, wet wool, and dirty dish rag. Most research agrees on 2-aminoacetophenone and other less well-identified compounds generated by degradation of indole-3-acetic acid as the causal agents. This chemical pathway is controlled by the oxygen radical scavenging capacity of the wine, which, in turn, is highly influenced by viticultural stress factors as the ultimate cause. Although oxygen is involved, atypical aging is distinct from premature oxidative aging with its own set of sensory and chemical descriptors.
\end{abstract}

Key words: 2-aminoacetophenone, indole-3-acetic acid, viticultural stress, off-flavor, aging, radical scavenging activity

Atypical aging (ATA), also known as untypical aging, is an aroma defect occurring in Vitis vinifera white wines and first referred to by anecdotal reports from Germany at the end of the 1980s. Since then, it has been observed in most winegrowing countries worldwide. However, the attention paid to ATA by producers and consumers is highly variable and does not necessarily reflect the frequency of its real occurrence in a given wine-growing area. It is not assumed to be a distinctive fault in some countries and may even be considered as an intrinsic expression of terroir in others.

It is generally accepted that the ultimate cause of ATA is a stress reaction in the vineyard triggered by various climatic, pedological, and viticultural factors. However, there is less consensus about its chemical and sensory characterization. While it is ascribed to a lack of varietal aroma compounds in some reports, most of the research has focused on 2-aminoacetophenone (AAP) as one of the major odor-active compounds responsible for the off-flavor. AAP is generated by degradation of indole-3-acetic acid (IAA) following the first addition of sulfur dioxide postfermentation. IAA has been extensively investigated as a precursor of AAP. IAA originates from both fruit and yeast metabolism, and its conversion rate into AAP depends primarily on wine composition as affected by viticultural factors and, to a lesser extent, by yeast and its nutritional supply. Thus, ATA is the result of a combination of plant stress and microbiological stress. Viticultural, microbiological, and enological factors affecting its formation are discussed in detail herein.

The connection of the off-flavor to some kind of aging process is misleading since ATA may appear in rather young

\footnotetext{
${ }^{1}$ Schneider-Oenologie, Am Entenbach 5, 55411 Bingen, Germany.

*Corresponding author (schneider.oenologie@gmail.com)

Manuscript submitted Jan 2014, revised Apr 2014, accepted Apr 2014

Copyright (C) 2014 by the American Society for Enology and Viticulture. All rights reserved.

doi: 10.5344/ajev.2014.14014
}

white wines within a few weeks or months after alcoholic fermentation and addition of sulfur dioxide. As a consequence, its occurrence may not be expected or may simply be ignored due to deficient sensory training. The sensory identification of ATA is complicated by its diverse forms of aromatic expression evoked by variable amounts of underlying odoriferous compounds in a complex flavor matrix.

\section{Chemical Composition and Sensory Discrimination}

AAP has been described as the chemical marker and sensory impact compound of ATA (Rapp et al. 1993). Its smell is similar to that of acacia blossom and mothballs. Thus, various analytical methods for measuring AAP have been proposed (Dollmann 1997, Dollmann et al. 1996a, Fan et al. 2009, Gulan and Arzberger 2008, Košmerl and Zlatić 2009, Rapp et al. 1993, Schmarr et al. 2007). In spiking trials conducted by some of these authors, increasing amounts of AAP added to sound wines showed positive correlations with perceived ATA intensity. Respective correlation coefficients were specified as $r=0.80$ (Christoph et al. 1995) and $r=0.66$ (Schneider 2013a), whereas in wine obtained from a long-term field study, AAP concentration accounted for only $30 \%$ of sensory untypical aging intensity (Linsenmeier et al. 2007a). According to these authors, and depending upon the wine matrix, the detection threshold varies from 0.5 to $1.5 \mu \mathrm{g} / \mathrm{L}$ AAP. Strongly aromatic wines are able to integrate greater than $1.5 \mu \mathrm{g} / \mathrm{L} \mathrm{AAP,} \mathrm{while}$ meager wines might be rejected as tainted by ATA with less than $0.5 \mu \mathrm{g} / \mathrm{L}$ AAP.

Contrary to spiking trials with AAP, when wines actually affected by ATA are submitted to descriptive sensory analysis, they usually show a poor correlation between AAP concentration and perceived ATA intensity. The aroma patterns are also different from those elicited by pure AAP. Additions of AAP alone fail to produce the whole sensory spectrum of ATA, although it is clearly involved in the off-flavor in many wines, particularly in Europe. These results strongly suggest not only masking effects but also the participation 
of compounds other than only AAP (Cheng et al. 2004, Christoph et al. 1995, Fischer and Sponholz 2000, Gessner et al. 1995, 1999a, Linsenmeier et al. 2007a, Pour Nikfardjam et al. 2005, Schneider 2013a, Simat et al. 2004).

While the conclusions above were obtained under European cool-climate conditions, AAP was reported to be below the sensory detection threshold in wines described as tainted by ATA under specific New York growing conditions (Cheng et al. 2004, Henick-Kling et al. 2008). These authors ascribe the perception of ATA as a combination of a loss of varietal fruit flavor causing stimulants like terpenols or their psychophysical suppression and the appearance of specific ATA off-flavor attributes. Confusing the lack of any flavor with ATA has been reported from the European context (Schneider 2013a). Differences of the expression of this flavor defect at different stages of the wine age and differences in language use make it difficult to compare descriptions.

On occasion, ATA is mistaken as a reduction flavor. More often, however, ATA and reduction flavor occur simultaneously (Rauhut et al. 2003, Sponholz and Hühn 2001). Since the volatile sulfur compounds responsible for reduction flavor are basically traced back to yeast metabolism as a response to nitrogen deficiency in fruit from stressed vineyards, viticultural stress is a common cause for both ATA and reduction flavor. When ATA is masked by reduction flavor, it can only be detected after copper fining removes the volatile sulfur compounds. A sample treatment with copper ions better reveals ATA and helps identify it.

Frequently, ATA is confounded with typical aging, which is a more slowly progressing process largely based on oxidation reactions, or even with premature oxidative aging, also known as premox. While ATA and oxidative aging may occur simultaneously in some wines, their aroma patterns are totally different. The need for more semantic precision in the description of the various forms of white wine aging has been emphasized for a number of years (Hühn and Gafner 1997). Clearly, sensory bias seems to be responsible to a great extent for conflicting results in ATA research, and more semantic precision is needed to describe ATA.

In wines affected by ATA, a plethora of olfactory attributes can be detected (Christoph et al. 1995, Fischer and Sponholz 2000), which, with the objective of sensory classification, can be divided in two groups (Schneider 2013a). Group I includes mothballs, naphthalene, laundry detergent powder, soap, floor polish, furniture polish, antique wax, jasmine, acacia blossom, lemon blossom, dry linen, and fusel alcohols. This odor pattern is reinforced by high concentrations of free sulfur dioxide. Group II includes damp towel, wet wool, dirty dish rag, washing machine, and urine deposits. This aroma profile marks the sensory transition to reduction flavor and may complicate the sensory identification of ATA. In either case, the fruity, floral, or mineral varietal aromatics disappear to a great extent, partially driven by acid-catalyzed ester hydrolysis and oxidation of monoterpenes associated with normal wine aging. Thus, the sensory intensity of ATA will increase over time. On the palate, tainted wines often come out meager and thin, displaying a metallic bitterness, some astringency, and a light color.
In affected wines, the attributes of either one or the other group can be dominant or occur concurrently. They interact with different aroma compounds present in the normal aroma matrix of the wine, resulting in a kind of mixed flavor. Taking into account these different sensory characteristics of ATA as well as diverging perceptions among tasters, it seems unfeasible to evaluate ATA as the intensity of a not precisely defined sensory attribute (Fischer and Sponholz 2000). There are so many ambiguous terms that tend to lack meaning.

Additions of AAP to sound wines evoked only aroma attributes referred to in group I above and described as acacia blossom and mothballs, whereas the "stinky" descriptors of group II could not be generated in any wine (Schneider 2013a). The group II set of descriptors is assumed to be more related to other compounds resulting from IAA catabolism as indole and skatole (3-methylindole). However, among these compounds, indole, vitispirane, guaiacol, anthranilic acid ethylester (Christoph et al. 1995, Gessner et al. 1999a) and methional (Rauhut et al. 2003) were reported to occur in ATA-tainted wines below their sensory threshold. More controversial is the role of skatole. In one study on affected wines, its concentrations were found to be below their sensory threshold of 1 to $3 \mu \mathrm{g} / \mathrm{L}$ (Linsenmeier et al. 2007a), while another study reported concentrations close to $10 \mu \mathrm{g} / \mathrm{L}$ (Hühn et al. 1999a). Reliable data on the sensory impact of skatole are not available, but since skatole displays a strong fecal odor, it is able to elicit the olfactory attributes of group II (Schneider 2013a). More research on the role of skatole is suggested.

In summary, the chemical causes of ATA have not yet been conclusively investigated. Under European conditions, AAP seems to be playing a role in the chemical make-up of ATA, but AAP was not consistently associated with ATA in New York wines. Again, more sensory agreement on what is ATA is needed, identifying more specific compounds involved in this kind of off-flavor.

\section{Microbiological Formation of AAP}

2-Aminoacetophenone (AAP) is partially responsible for the "foxy" smell of non-vinifera varieties, but does not occur in grapes and juices from $V$. vinifera (Acree et al. 1993). During alcoholic fermentation under stress conditions in a synthetic medium containing IAA as precursor, yeast metabolism was shown to produce significant amounts of AAP, skatole, and indole, but did not do so in natural juices (Hühn 2003a, Hühn et al. 1999a). The synthesis of these compounds was enhanced by specific nutritional conditions comprising a lack of pantothenate and the concurrent presence of aromatic amino acids (Ciolfi et al. 1995). In model solutions containing neither IAA nor L-tryptophan, AAP was generated from L-kynurenine during fermentation with Saccharomyces cerevisiae (Dollmann et al. 1996b).

In fermentation media containing IAA as in natural musts, however, L-kynurenine was ruled out as a precursor of AAP (Hoenicke et al. 2002a). Under these conditions, IAA was considered the relevant precursor. It was converted into AAP by yeast metabolism in must with a conversion rate of merely 0.06 to $0.08 \mathrm{~mol} \%$ (Gessner et al. 1996, Hühn et al. 1999a). 
Regarding a natural pool of total IAA in grape musts of approximately $100 \mu \mathrm{g} / \mathrm{L}$ (Hoenicke et al. 2001b, Simat et al. 2004), this conversion rate will yield only $0.07 \mu \mathrm{g} / \mathrm{L}$ AAP. A maximum formation of $0.4 \mu \mathrm{g} / \mathrm{L}$ AAP during fermentation was observed (Gessner et al. 1996). These amounts are clearly below the odor threshold.

The fermentation results indicate that the formation of AAP by yeast is not a significant contributor to the AAP found in wine as long as fermentations are carried out by S. cerevisiae strains in natural musts. They corroborate the general finding under commercial winemaking conditions that the synthesis of odor-active amounts of AAP and the appearance of ATA are not the direct consequence of yeast metabolism and that they cannot be observed immediately after fermentation without further interventions on the wine. This may not always be the case when juices are submitted to spontaneous fermentation involving non-Saccharomyces strains (Sponholz et al. 1997, Simat et al. 2004).

\section{Metabolism of the Precursor IAA}

IAA is a phytohormone occurring in grapes and one of the intermediate products of the tryptophan metabolism of yeast, but the only one able to act as a potential precursor of AAP. When winelike model solutions containing IAA were spiked with sulfites, $50 \%$ of the IAA disappeared within a few weeks, yielding 0.5 to $20 \mathrm{~mol} \%$ AAP and a large array of various other compounds not all identified. In wines spiked with IAA, the conversion rate was only 0.5 to $3.0 \mathrm{~mol} \%$ for white and $0 \mathrm{~mol} \%$ for red wines, depending on time and temperature. The presence of free sulfur dioxide is indispensable to induce the reaction. As a consequence, for average concentrations of nonbound IAA in white wine of $\sim 100 \mu \mathrm{g} / \mathrm{L}$ at the time point of sulfiting, the formation of sensorially relevant concentrations of greater than $1 \mu \mathrm{g} / \mathrm{L}$ AAP is possible within a few weeks after $\mathrm{SO}_{2}$ addition. Intermediate products of the tryptophan metabolism other than IAA are far less able to produce AAP (Christoph et al. 1998, Hoenicke et al. 2002a).

With IAA acting as the primary precursor, it could be assumed that its concentration in young wines should be of importance for the propensity of a wine to produce ATA. Research on IAA metabolism showed that it occurs almost exclusively in bound forms in grape must, while its free form, which is able to react in the presence of sulfites, is nearly absent. Only during fermentation, reasonable amounts of free IAA are produced by hydrolysis of bound IAA and neosynthesis from tryptophan by the yeast (Christoph et al. 1996, Hoenicke et al. 1999, 2001a, 2001c, Maslov et al. 2011). Tryptophan is completely consumed by yeast and converted into different compounds, of which less than $5 \mathrm{~mol} \%$ is IAA (Simat et al. 2004).

Juices from late harvested grapes display more IAA than those from early harvested grapes. However, after fermentation, wines made from late harvested grapes tend to show lower levels of free IAA than wines obtained from early harvested grapes of the same vineyard. The amount of free IAA at the time of sulfiting is influenced more by yeast metabolism and fermentation conditions than by the initial IAA content in the must. Wild yeasts (Kloeckera apiculata, Metschnikowia pulcherrima) produce higher amounts of free IAA than strains of $S$. cerevisiae. Fermentation on the skins, addition of complex yeast nutrients, and lower fermentation rates at cool temperatures reduced the content of nonbound IAA in the wines (Hoenicke et al. 2001b, 2002b, Simat et al. 2004, Maslov et al. 2011).

The significance of IAA concentrations in wine is not conclusive. In one study, there was a significant but low correlation found between the content of nonbound IAA prior to sulfiting and the amount of AAP in the wine, indicating that 30 to $50 \%$ of the AAP concentration might be traced back to the amount of the precursor IAA at the time point of sulfur dioxide addition. This indicates that relevant factors other than the amount of unbound IAA must influence AAP formation (Simat et al. 2004).

In other investigations, neither the amount of total IAA in the must nor the content of free IAA in the wine at the time of sulfiting showed a positive correlation with the formation of AAP. There was even a negative correlation between IAA in juice and perceived ATA in wine. Thus, the appearance of ATA seems not to be linked to a higher amount of IAA in the fruit, must, or wine (Hoenicke et al. 2001b, 2002b, Linsenmeier et al. 2007b, Linsenmeier and Pfliehinger 2009, Steinhart et al. 2001). Although IAA is the precursor of AAP, its amount is not a reliable means to predict the propensity of a wine to produce ATA. Matrix effects are more important since they control the conversion rate of IAA into AAP. This is particularly demonstrated in red wines. Although IAA levels in red wines are approximately 10 times higher than levels in white wines (Bonerz et al. 2008), they never display ATA.

\section{Factors in the Conversion of IAA into AAP}

The first step in this reaction is a non-enzymatic oxidation in which the pyrrole ring of IAA is oxidized by oxygen radicals formed during the aerobic oxidation of sulfite to sulfate. Alternatively, the role of manganese as a potential oxidizing agent has been discussed. By decarboxylation before or after pyrrole oxidation and cleavage of the indole ring, a reaction sequence comprising 3-methylindole (skatole) and 2 -formylacetophenone gives rise to the appearance of AAP. Compound structure and reaction pathways have been described (Christoph et al. 1999, Hoenicke et al. 2002a, 2002b). Without addition of sulfites, the reaction does not take place. In conclusion, sulfite triggers the chemical conversion of IAA into AAP (Christoph et al. 1998, 1999, Hoenicke et al. 2002a). The potential role of skatole as potentially contributing to ATA is discussed above.

Using different radical generation systems, it could be shown that especially superoxide radicals are responsible for the formation of AAP and other compounds by pyrrole ring cleavage of IAA. Antioxidants with a superoxide radical scavenger activity such as phenolic compounds can reduce the tendency to ATA formation. Their amounts seem to depend on the ripeness of the grapes. Wines made from late 
harvested grapes revealed significantly higher antioxidative capacity and lower sensory ratings for ATA than wines from early harvested grapes. Red wines are reputed to be protected against ATA by their high tannin content acting as a radical scavenger (Hoenicke et al. 2002b).

On the other hand, in model wines containing only sugar, yeast, free IAA, and inorganic nitrogen, AAP formation upon addition of sulfur dioxide before fermentation was 10 times less than in the alcoholic medium after fermentation. This observation indicates that yeast may be involved in AAP production by other ways than the formation of nonbound IAA (Christoph et al. 1998), but might also imply that alcohol plays a role. However, the impact of ethanol on the nonenzymatic conversion of IAA into AAP has not yet been investigated. Wine pH was shown to have no influence (Zapušek 2007).

The formation of oxygen radicals bringing about this conversion requires the intermittent availability of dissolved oxygen (DO). However, when sulfur dioxide is added to young white wines, the wines are usually not yet filtered and contain significant amounts of suspended yeast cells known for their ability to consume DO, raising the issue of where the oxygen originates. In adding controlled amounts of oxygen to model solutions containing a typical concentration of $100 \mu \mathrm{g} / \mathrm{L}$ IAA, it was shown that levels as low as 0.15 to $0.50 \mathrm{mg} / \mathrm{L} \mathrm{DO}$ are sufficient to produce the typical smell of UTA. These minute amounts are inevitably taken up even when wines are carefully protected against oxygen ingress during cellar operations, but are far too low to elicit any oxidative aging and explain why, despite the involvement of oxygen, ATA must be distinguished from oxidative aging from a sensory and chemical point of view (Schneider 2013b). As a consequence, postfermentation oxygen management does not impact the appearance of ATA nor does the variable oxygen transmission rate of bottle closures.

\section{Viticultural Origins and Countermeasures}

Technical reports on empirical evidence refer to overcropping, premature harvest, drought, green cover, and reduced fertilization as the main viticultural factors triggering ATA under cool-climate growing conditions (Amann et al. 2001, Cheng et al. 2004, Jakob 1993, Köhler et al. 1995, Löhnertz 1996, Müller 1999, Schwab et al. 1996). These factors induce a physiological stress in the vine or impact ripeness adversely with the appearance of ATA as a result. However, exceptions to the rule exist for each factor. Frequently, they are linked one to another, thereby making it difficult to identify one factor as the sole cause of ATA.

Ripeness. Wines obtained from late harvested grapes tend to be less afflicted by ATA than those produced from early harvested fruit from the same plot (Gessner et al. 1995, Schwab et al. 1999, Hoenicke et al. 2001b, 2002b, Simat et al. 2004). The combination of premature harvest and high crop load tends to predispose wines strongly to the formation of ATA.

Soluble solids in the juice, however, are an equivocal parameter for evaluating the propensity of a wine to develop
ATA. One study showed no relationship between the occurrence of ATA and Brix readings (Linsenmeier et al. 2007a), while other authors reported Brix readings and alcohol content to correlate negatively with perceived ATA intensity (Gessner et al. 1995, Köhler et al. 1995). Since ATA may also appear in wines obtained from fruit with high Brix readings grown under hot-climate conditions, traditional Brix figures are considered to reflect only alcoholic ripeness as opposed to aromatic ripeness, the latter precluding the formation of ATA (Schneider and Almeida 2005).

Yeast assimilable nitrogen (YAN) in the juice showed a weak correlation with the propensity of wine to develop ATA. However, this correlation is not a causal one. While low YAN levels indicate a high propensity for ATA formation, high YAN levels do not exclude it (Amann et al. 2001, Sponholz and Hühn 2001). Taken as a whole, there are not yet any reliable analytical tools to predict ATA by analysis of the fruit.

Nutrient deficiencies. Research on the impact of nitrogen $(\mathrm{N})$ status and fertilization has given inconsistent results. Under cool-climate conditions, increased $\mathrm{N}$ fertilization was reported to reduce the occurrence and intensity of ATA (Schwab et al. 1996, Seiter 2000) or to be without any effect (Müller 1999). It did not impact tryptophan or IAA concentrations (Linsenmeier et al. 2004). Drought-induced low nitrogen status during veraison and early fruit ripening was considered to trigger ATA formation, while both irrigation and foliar $\mathrm{N}$ application reduced off-flavors associated with ATA and improved varietal aroma character (Cheng et al. 2004).

In a long-term experiment, variable $\mathrm{N}$ fertilization affected AAP concentration in the wine as much as the growing conditions during the year. Generally, AAP concentration and ATA intensity increased with increasing $\mathrm{N}$ fertilization. This result is explained by the antioxidant capacity of the wines which decreased with increasing $\mathrm{N}$ fertilization. Antioxidant capacity as measured by chemoluminescence accounted for 13 to $67 \%$ of the total variance of ATA. Antioxidants such as phenols were exerting a masking effect on ATA intensity. However, $\mathrm{N}$ fertilization regimes are not sufficient to explain ATA. Despite significant effects of the growing conditions and of the fertilization regime accounting for $\sim 20 \%$ of the total variance, a high residual variance accounting for more than $50 \%$ of the total variance of ATA intensity in wine could not be explained. Grape yield was positively correlated with ATA, but accounted for only $10 \%$ of the variance. As a conclusion, fertilization with $60 \mathrm{~kg} / \mathrm{ha} \mathrm{N}$ is recommended, while higher amounts increase the propensity of the wines to produce ATA (Linsenmeier et al. 2007a, 2007b).

Hydric stress and irrigation. Since ATA occurs primarily in wines from harvests characterized by dry summers, drought stress during ripening has been shown to be one of the most important causes of ATA. As cover crops compete for water and $\mathrm{N}$, the effect of drought is reinforced under conditions of green cover. Soil treatment (Schwab et al. 1996, 1999, Sponholz et al. 1997, Sponholz and Hühn 2001), irrigation (Cheng et al. 2004, Henick-Kling et al. 2008), and application of farmyard manure (Schwab and Peternel 1997) decrease perceived ATA intensity. Especially for vineyard 
soils with low water-holding capacity, it is recommended to remove green cover by mulching or plowing in alternate rows around budbreak.

In some wines obtained under New York growing conditions, the ATA flavor defect correlated with TDN (1,1,6-trimethyl-1,2-dihydronaphthalene), the causal agent of the so-called petrol flavor. This observation suggests that the pathways of TDN and ATA formation are linked but that an additional trigger is needed to cause the formation of the ATA flavor defect. While heat stress alone can cause the TDN offflavor, an additional drought stress at some critical point during the ripening period might be the principal reason for ATA. It can be assumed that in water-stressed vines the berries also overheat due to a lack of canopy shade (Henick-Kling et al. 2008). These results show that TDN can also be associated with ATA just as in the case where a sulfur off-odor is present in ATA wines, as discussed earlier. This further complicates its description and accurate sensory identification.

UV-radiation. Under viticultural stress situations, protection from UV-B radiation by repeated spraying of a synthetic UV-B absorption reagent resulted in lower AAP concentration in the wine (Hühn 2003b). This is explained by the fact that metabolites of tryptophan degradation absorb UV light, inducing a photochemical reaction susceptible to contribute to the formation of compounds involved in ATA. Simultaneously, YAN in the juice was increased. Foliar nitrogen fertilization showed similar effects (Hühn 2003a, Hühn et al. 2003).

\section{Enological Measures against ATA}

Yeast strain and yeast nutrients. Commercially available active dry yeast strains showed significant differences in their ability to produce IAA in identical juices (Mihaljević et al. 2012). IAA can produce AAP, which is involved in the ATA off-flavor in many affected wines. Thus, some authors considered IAA metabolism of yeast decisive for the formation of ATA since it strongly affects the content of IAA as the precursor of AAP (Christoph et al. 1999, Hoenicke et al. 2001b, 2002b), while other researchers found no correlation between IAA and AAP concentrations (Linsenmeier et al. 2007b, Linsenmeier and Pfliehinger 2009).

If AAP were the only causative agent of ATA, then the direct link between yeast strain and AAP concentration in the resulting wine would be important. After inoculation of an identical juice with two different $S$. cerevisiae yeast strains, AAP in the one-year-old wine was 0.6 and $1.1 \mu \mathrm{g} / \mathrm{L}$, respectively (Rauhut et al. 2003). It is not clear whether these amounts resulted directly from yeast metabolism or were produced by the chemical pathway postfermentation. Other authors reported active dry yeast strains to produce only very low amounts of AAP during fermentation not exceeding 0.4 $\mu \mathrm{g} / \mathrm{L}$ and, therefore, below the odor threshold (Gessner et al. 1996, Hühn 2003a). Nevertheless, inoculation with wild yeast strains and spontaneous fermentations were shown to cause higher amounts of AAP (Sponholz et al. 1997, Simat et al. 2004). Yeast strains producing strong fermentation aromatics can delay the appearance of ATA by masking effects, but not prevent it (Köhler et al. 1996).
Likewise, the effect of yeast nutrients is not conclusive. While some authors (Köhler et al. 1996, Hoenicke et al. 2001b, Bach 2005, Lorenzini 2009) reported no significant impact of juice supplementation with diammonium hydrogen phosphate (DAP) and inactive yeasts on AAP concentration or ATA intensity, another investigation showed that DAP can decrease the amount of AAP (Rauhut et al. 2003). This effect is ascribed to an interception of oxygen radicals by metabolic products of the yeast as glutathione.

Obviously, yeast strain and nutrition status have some impact on perceived ATA intensity. Differences between yeast strains in AAP synthesis, release of radical scavengers, and production of masking fruity aromas play a role. However, ATA is not a by-product of alcoholic fermentation, but rather a legacy of stress in the vineyard. Thus, the choice of an active dry yeast strain cannot be considered an appropriate tool to mitigate ATA. The crucial parameters of wine composition affecting the conversion of IAA into AAP are the result of vineyard management.

Prefermentation strategies. Skin contact has been shown to decrease AAP concentration by $35 \%$ (Bach 2005) and perceived ATA intensity (Wohlfahrt 1993). This effect is partially ascribed to an increased extraction of grape phenols able to scavenge oxygen radicals involved in the chemical conversion of IAA into AAP (Gessner et al. 1996, Linsenmeier et al. 2007a). Accordingly, wines obtained from free-run juice are more prone to produce ATA due to their lower total phenol content than the wine from pressed juice (Amann et al. 2001). However, additions of press fractions showed no significant effect in other experiments (Hoenicke et al. 2001b). Higher concentrations of varietal fruit aromatics extracted during skin contact and pressing play possibly an additional role in the sensory perception of ATA by masking it.

Although juice oxidation is known to decrease the concentration of phenols by oxidative precipitation, the extent of that effect did not increase ATA intensity (Köhler et al. 1996). However, active oxygenation and hyperoxidation should be avoided on juices obtained from stressed fruit, and nitrogen instead of air should be used when they are clarified by flotation (Lipps 2005).

Juice clarification is seen as an important step to reduce ATA potential in the resulting wines (Wohlfahrt 1993, Pohl 1994). The residual juice turbidity is far more important than the technical means used to achieve it. The fermentation of juice bottoms is very likely to produce ATA in the resulting wine while the clarified juices do not, suggesting that a large fraction of the precursor is bound to insoluble solids (Schneider 2013a).

Postfermentation strategies. Flavor intensity of ATA increases with wine age as expected (Köhler et al. 1996, Gessner et al. 1999a, Cheng et al. 2004), and older wines contain higher concentrations of AAP than younger ones (Košmerl and Zlatić 2009). Wine storage at low temperatures can delay the formation of ATA, but cannot prevent it.

Storage on the lees during 10 months in barrels decreased the AAP concentration from 0.2 to $0 \mu \mathrm{g} / \mathrm{L}$. The effect was ascribed to the radical scavenging activity of glutathione and 
other reducing amino acids released from the yeast biomass (Lavigne-Cruege et al. 2000). Since the initial level of AAP was far below its sensory threshold, it remained ambiguous whether this effect could contribute to a significant decrease of sensorially relevant amounts. This question was answered by other studies carried out under commercial winemaking conditions and demonstrating that storage on the lees (Köhler et al. 1996), even with weekly bâtonnage (Lorenzini 2009), had no impact on perceived ATA intensity. Thus, the time point of racking and filtration is not relevant.

Additions of inactivated yeast postfermentation failed to prevent ATA (Bach 2005). Supplements of tannins (100 mg/L) before and after alcoholic fermentation did not diminish the formation of AAP while supplements of pure glutathione (20 to $150 \mathrm{mg} / \mathrm{L}$ ) did so in some wines, depending on the yeast strain. Only the addition of ascorbic acid ( 75 and $150 \mathrm{mg} / \mathrm{L}$ ) prevented the formation of AAP and ATA systematically (Rauhut et al. 2003). Although yeast nutrients and metabolites might improve the antioxidant capacity of wine, their effect does not equal that of ascorbic acid.

The addition of 100 to $250 \mathrm{mg} / \mathrm{L}$ ascorbic acid in a timely manner is the only effective means to protect wines against ATA over a period of at least three years. It has been successfully implemented under commercial winemaking conditions in wines from vineyards with a history of producing wines prone to develop it (Gessner et al. 1999a, 2000, Köhler et al. 2001). The addition of ascorbic acid is recommended to take place at or before the first addition of sulfur dioxide after alcoholic fermentation. Additions at a subsequent time point are possible and sufficient to prevent intensification of an existing ATA off-flavor. However, such additions are not able to mitigate it; the reactions involved in the formation of ATA are irreversible. During further storage and cellar operations, wines treated in this way must be kept with adequate levels of free sulfur dioxide and carefully protected from oxygen uptake to avoid the autoxidation of ascorbic acid. No fining or other treatments have been shown capable of remedying spoiled wines.

Evaluation of the propensity for ATA. Viticultural measures cannot avoid ATA with certainty, and there are not yet any reliable analytical techniques available to predict a wine's propensity for developing ATA (Linsenmeier et al. 2007a, 2007b). Instead, an accelerated aging test has been proposed and widely introduced into practice (Gessner et al. 1999b): a clarified sample of wine containing at least $40 \mathrm{mg} / \mathrm{L}$ free $\mathrm{SO}_{2}$ is poured into two flasks, one of them receiving an additional supplementation of $150 \mathrm{mg} / \mathrm{L}$ ascorbic acid. Both flasks are stored at 37 to $45^{\circ} \mathrm{C}$ for three to four days. After cooling down, both samples are evaluated by smell. If the sample without ascorbic acid addition displays ATA, then the wine is prone to develop it. A wine spiked with AAP is recommended as a reference for less trained evaluators.

\section{Conclusions}

The sensory characterization of ATA includes a premature loss of fruity varietal aroma combined with an increase in off-flavors that range from mothballs, furniture polish, and acacia blossom to damp towel and dirty laundry, as well as its distinctiveness from ordinary oxidative aging. Much of the conflicting results in ATA research might be tracked back to inadequate sensory discrimination. Any further investigation will be seriously biased as long as no commonly accepted agreement on its sensory characterization is achieved.

The overwhelming majority of reports ascribe the offflavor to the presence of AAP and other less investigated compounds resulting from oxidative degradation of IAA postfermentation. However, a number of studies do not support this association, but failed to conclusively specify any other sensory impact compound.

The degradation reaction of IAA is induced by oxygen radicals resulting from aerobic oxidation of sulfites added postfermentation. The formation of AAP requires only a brief exposure to trace concentrations of dissolved oxygen, concentrations that are incapable of causing any perceptible oxidative aging. Minimizing oxygen uptake during cellar operations cannot impede the reaction. However, ascorbic acid has proven to effectively scavenge the oxygen radicals and to be the only technical means to prevent ATA in wines prone to develop it.

The radical scavenging effect of ascorbic acid added to white wines is similar to that of tannins preventing the formation of ATA in red wines, showing that an oxidation is involved in the formation of ATA that is controlled by the wine matrix. It has been shown that the addition of ascorbic acid blocks or strongly inhibits the formation of AAP, indicating that AAP is a sensory impact compound responsible for ATA in many wines. However, there is no close correlation between the amount of IAA at the time point of sulfiting, the concentration of AAP produced, and perceived ATA intensity.

Viticultural stress factors including drought, UV-B radiation, nutrient deficiencies, overcropping, and premature harvest are at the very origin of a wine matrix prone to produce ATA. Enological factors play a minor role, although skin contact and yeast strain have some impact as far as they affect the presence of oxygen radical scavengers like polyphenols and yeast metabolic products. Further research on ATA is required to better understand its viticultural causes and their interdependencies, to depict the whole array of compounds involved in its sensory perception, to evaluate the radical scavenging activity of the affected wines, and to standardize its sensory characterization.

\section{Literature Cited}

Acree, T.E., E.H. Lavin, and K. Shure. 1993. The aroma of nonvinifera grapes. In Connaissance aromatique des cépages et qualité des vins. Rev. Fr. d'Enologie (ed.), pp. 51-57. Actes du Symposium International, Montpellier, France.

Amann, R., J. Sigler, and H. Krebs. 2001. Wenig Stickstoff im Most = viel UTA? Badischer Winzer 9:16-21.

Bach, H.P. 2005. Untypischen Alterungston vermeiden. WinzerZeitschrift 9:32-34.

Bonerz, D.P.M., M.S. Pour Nikfardjam, and G.L. Creasy. 2008. A new RP-HPLC method for analysis of polyphenols, anthocyanins, and indole-3-acetic acid in wine. Am. J. Enol. Vitic. 51:106-109.

Cheng, L, A. Lakso, T. Henick-Kling, T. Martinson, and T. Acree. 2004. Conclusions for three years of study on the effect of drought 
stress and available nitrogen on the formation of atypical aging flavor defect in wine. In Proceedings of the 33rd Annual New York Wine Industry Workshop. T. Henick-Kling (ed.), pp. 68-71. Cornell University, Geneva, NY.

Christoph, N., C. Bauer-Christoph, M. Gessner, and H.J. Köhler. 1995. Die "Untypische Alterungsnote" in Wein, Teil I: Untersuchungen zum Auftreten und zur sensorischen Charakterisierung der Untypischen Alterungsnote. Rebe Wein 48:350-356.

Christoph, N., C. Bauer-Christoph, M. Gessner, and H.J. Köhler. 1996. Die "Untypische Alterungsnote" in Wein, Teil VI: Untersuchungen zur Bildung von 2-Aminoacetophenon aus Produkten des TryptophanStoffwechsels vor der alkoholischen Gärung. Rebe Wein 49:246-250.

Christoph, N., C. Bauer-Christoph, M. Gessner, H.J. Köhler, T.J. Simat, and K. Hoenicke. 1998. Formation of 2-aminoacetophenone and formylaminoacetophenone in wine by reaction of sulfurous acid with indole-3-acetic acid. Vitic. Enol. Sci. 53(2):79-86.

Christoph, N., M. Gessner, T.J. Simat, and K. Hoenicke. 1999. Offflavor compounds in wine and other food products formed by enzymatical, physical, and chemical degradation of tryptophan and its metabolites. Adv. Exp. Med. Biol. 467:659-669.

Ciolfi, G., A. Garafolo, and R. di Stefano. 1995. Identification of some o-aminophenones as secondary metabolites of Saccharomyces cerevisiae. Vitis 34:195-196.

Dollmann, B. 1997. Studien zur Analytik und Bildung von 2-Aminoacetophenon in Weinen mit Fehlaroma. Thesis, University of Würzburg, Germany.

Dollmann, B., D. Wichmann, A. Schmitt, H.J. Köhler, and P. Schreier. 1996a. Quantitative analysis of 2-aminoacetophenone in off-flavored wines by stable isotope dilution assay. J. AOAC Int. 79:583-586.

Dollmann, B., D. Wichmann, A. Schmitt, H.J. Köhler, and P. Schreier. 1996b. Formation of the untypical off-flavour in wine: Generation of 2-aminoacetophenone in model studies with Saccharomyces cerevisiae. Vitic. Enol. Sci. 51(2):122-155.

Fan, W., I. Tsai, and M. Qian. 2009. Analysis of 2-aminoacetophenone by direct-immersion solid-phase microextraction and gas chromatography-mass spectrometry and its sensory impact in Chardonnay and Pinot gris wines. Food Chem. 105:1144-1150.

Fischer, U., and R. Sponholz. 2000. Die sensorische Beschreibung der Untypischen Alterungsnote. Deut. Weinbau 3:16-21.

Gessner, M., H.J. Köhler, N. Christoph, C. Bauer-Christoph, R. Miltenberger, and A. Schmitt. 1995. Die "Untypische Alterungsnote" in Wein, Teil II: Beschreibende Verkostung von UTA-Weinen; Beziehungen zwischen Sensorik und chemisch-physikalischen Analysenwerten. Rebe Wein 11:388-394.

Gessner, M., H.J. Köhler, N. Christoph, and C. Bauer-Christoph. 1996. Die "Untypische Alterungsnote" in Wein, Teil VII: Untersuchungen zur Bildung von 2-Aminoacetophenon aus Produkten des TryptophanStoffwechsels bei der alkoholischen Gärung. Rebe Wein 49:251-255.

Gessner, M., H.J. Köhler, and N. Christoph. 1999a. Die "Untypische Alterungsnote" in Wein, Teil VIII: Auswirkungen von Inhaltsstoffen und Antioxidantien auf die Bildung von o-Aminoacetophenon. Rebe Wein 51:264-267.

Gessner, M., H.J. Köhler, N. Christoph, A. Nagel-Derr, and U. Krell. 1999b. Die "Untypische Alterungsnote" in Wein, Teil IX: Würzburger UTAFIX-Test: Ein einfaches Diagnoseverfahren zur Früherkennung von Weinen mit UTA-Neigung. Rebe Wein 52:296-303.

Gessner, M., H.J. Köhler, N. Christoph, and A. Nagel-Derr. 2000. Erfahrungen zum Weinausbau mit Ascorbinsäure; Durchbruch bei der UTA-Behandlung. Deut. Weinmagazin 19:34-37.

Gulan, S., and U. Arzberger. 2008. Quantification of 2-aminoacetophenone in white wine by headspace solid phase micro extraction and gas chromatography-mass spectrometry. Deut. Lebensm-Rundsch. 6:41-45.
Henick-Kling, T., C. Gerling, T. Martinson, T. Acree, A. Lakso, and L. Chiang. 2008. Studies on the origin and sensory aspects of atypical aging in white wines. In Proceedings of the 15th International Enology Symposium, Trier, Germany, $10 \mathrm{pp}$. International Association of Enology, Management and Wine Marketing (eds.), Breisach, Germany.

Hoenicke, K., T.J. Simat, H. Steinhart, N. Christoph, H.J. Köhler, and A. Schwab. 1999. Determination of tryptophan and tryptophan metabolites in grape must and wine. Adv. Exp. Med. Biol. 467:671-677.

Hoenicke, K., T.J. Simat, H. Steinhart, H.J. Köhler, and A. Schwab. 2001a. Determination of free and conjugated indole-3-acetic acid, tryptophan, and tryptophan metabolites in grape must and wine. J. Agric. Food Chem. 49:5494-5501.

Hoenicke, K., M. Gessner, A. Schwab, T.J. Simat, and H. Steinhart. 2001b. Indolessigsäure in Mosten und Weinen - Relevanz als Precusor hinsichtlich der Ausbildung einer "Untypischen Alterungsnote" (UTA) in Wein. Lebensmittelchemie 55:146-156.

Hoenicke, K., T.J. Simat, H. Steinhart, M. Gessner, H.J. Köhler, A. Schwab, and N. Christoph. 2001c. Indole acetic acid in musts and wines-Importance with regard to the formation of an untypical ageing note (ATA) in wine. In Proceedings of the Sixth International Symposium of New Oenological Methods and Wine Quality, Stuttgart, Germany, pp. 113-119. International Association of Enology, Management and Wine Marketing (eds.), Breisach, Germany.

Hoenicke, K., O. Borchert, K. Grüning, and T.J. Simat. 2002a. Untypical aging off-flavor in wine: Synthesis of potential degradation compounds of indole-3-acetic acid and kyrurenine and their evaluation of precursors of 2-aminoacetophenone. J. Agric. Food Chem. 50:4303-4309.

Hoenicke, K., T.J. Simat, H. Steinhart, N. Christoph, M. Gessner, and H.J. Köhler. 2002b. Untypical aging off-flavor in wine: Formation of 2-aminoacetophenone and evaluation of its influencing factors. Anal. Chim. Acta 458:29-37.

Hühn, T. 2003a. Freisetzung und Bildung von Aromastoffen aus natürlichen Vorstufen durch Hefen. Thesis, University of Frankfurt, Germany.

Hühn, T. 2003b. Influence de l'environnement et des effets de substrat sur les substances déterminant la valeur du moût et du vin. Rev. (Enol. 30(109):41-45.

Hühn, T., and J. Gafner. 1997. Einflussfaktoren der vorzeitigen untypischen Weinalterung. Schweiz. Z. Obst-Weinbau 25:636-638.

Hühn, T., W.R. Sponholz, and M. Grossmann. 1999a. Release of undesired aroma compounds from plant hormones during alcoholic fermentation. Vitic. Enol. Sci. 54(4):105-113.

Hühn T., W. R. Sponholz, K. Bernath, A. Friedmann, G. Hess, H. Muno, and W. Fromm. 1999b. The influence of high-energy shortwave radiation and other environmental factors on the genesis of compounds affecting the wine quality in Vitis vinifera L. cv. MuellerThurgau. Vitic. Enol. Sci. 54(4):101-104.

Hühn, T., S. Cuperus, M. Pfliehinger, W.R. Sponholz, K. Bernath, W. Patzwahl, M. Grossmann, R. Amadó, J. Galli, and A. Friedmann. 2003. Influence of environment on the composition of substrates and related atypical ageing in white wines. In Enologie 2003. 7e Symposium International d'Enology. A. Lonvaud-Funel et al. (eds.), pp. 139-143. Lavoisier Tec \& Doc, Paris.

Jakob, K. 1993. Naphtalinton-lässt er sich vermeiden? Deut. Weinbau $13: 23-25$

Köhler, H.J., N. Christoph, M. Gessner, and C. Bauer-Christoph. 1995. Die "Untypische Alterungsnote" in Wein, Teil III: Zusammenhänge zwischen dem Auftreten der untypischen Alterungsnote und dem Reifestadium der Trauben (Lesetermin). Rebe Wein 48:424-430.

Köhler, H.J., N. Christoph, C. Bauer-Christoph, N. Gessner, and K. Curschmann. 1996. Die "Untypische Alterungsnote" in Wein, Teil V: Einfluss kellertechnischer Maßnahmen auf die Ausprägung der UTA. Rebe Wein 7:213-218. 
Köhler, H.J., M. Gessner, and N. Christoph. 2001. Vermeidung der Untypischen Alterungsnote: Ascorbinsäure als wichtige Hilfe. Deut. Weinbau-Jahrbuch 52:219-228.

Košmerl, T., and E. Zlatić. 2009. Determination of 2-aminoacetophenone in wines using the stir bar sorptive extraction method coupled with GC-MS and GC-NPD. Mitt. Klosterneuburg 59:121-126.

Lavigne-Cruege, V., I. Cutzach, and D. Dubourdieu. 2000. Interprétation chimique du vieillissement aromatique défectueux des vins blancs. Incidence des modalités d'élevage. In Enologie 99. 6e Symposium International d'EEnology. A. Lonvaud-Funel et al. (eds.), pp. 433-438. Lavoisier Tec \& Doc, Paris.

Linsenmeier, A., O. Löhnertz, and S. Schubert. 2004. Effect of different $\mathrm{N}$ fertilization of vine on the tryptophan, free and total indole3-acetic acid concentrations. Vitis 43(4):157-162.

Linsenmeier, A., D. Rauhut, H. Kürbel, O. Löhnertz, and S. Schubert. 2007a. Untypical ageing off-flavour and masking effects due to long-term nitrogen fertilization. Vitis 46(1):33-38.

Linsenmeier, A., D. Rauhut, H. Kürbel, S. Schubert, and O. Löhnertz. 2007b. Ambivalence of the influence of nitrogen supply on o-aminoacetophenone in Riesling wine. Vitis 46(2):91-97.

Linsenmeier, A., and M. Pfliehinger. 2009. Wirkungskette Stress-das ungeklärte UTA-Rätsel. Deut. Weinbau 24:18-21.

Lipps, M. 2005. UTA-Neigung von Weinen: Welche Auswirkungen haben Flotationsgase? Deut. Weinmagazin 19:32-35.

Löhnertz, O. 1996. UTA und Rebenernährung. Stress macht alt. Deut. Weinmagazin 18:18-23.

Lorenzini, F. 2009. Effet des lies sur le caractère de "stress" des vins. Essais sur Chasselas. Rev. Suisse Vitic. Aboric. Hortic. 41 (4):227-230.

Maslov, L., A. Jeromel, S. Herjavec, A.M.J. Korenika, Ž.M. Mihaljević, and T. Plavša. 2011. Indole-3-acetic acid and tryptophan in Istrian Malvasia grapes and wines. J. Food Agric. Environ. 9(3,4):29-33.

Mihaljević, Ž.M., A.M.J. Korenika, I. Puhelek, L. Maslov, I. Tomaz, and A. Jeromel. 2012. Influence of different yeast strains on metabolism of tryptophan and indole-3-acetic acid as the precursors of "Untypical Aging off-flavor" (UTA) in wine. In Book of Abstracts of the International Symposium for Agriculture and Food (eds.), pp. 55-56. Skopje, Mazedonia.

Müller, E. 1999. 15 Jahre Stickstoffdüngungsversuche: Erfahrungen und Konsequenzen. Deut. Weinmagazin 19:27-31/20:29-32.

Pohl, H. 1994. Zur Situation der untypischen Alterungsnote beim Wein aus der Sicht der Praxis. Badische Winzer 19(8):328-330.

Pour Nikfardjam, M.S., K. Gaál, P. Teszlák, M. Kreck, and H. Dietrich. 2005. Influence of grapevine flower treatment with gibberellic acid (GA3) on o-aminoacetophenone (AAP) content and sensory properties of white wine. Mitt. Klosterneuburg 55(5-6):184-190.

Rapp, A., G. Versini, and H. Ullemeyer. 1993. 2-Aminoacetophenone: Causal component of 'untypical aging flavour,' 'naphthalene note,' 'hybrid note' of wine. Vitis 32:61-62.
Rauhut, D., P.G. Shefford, C. Roll, H. Hürbel, and O. Löhnertz. 2003. Effect of diverse enological methods to avoid occurrence of atypical aging and related off-flavours in wine In Enologie 2003. 7e Symposium International d'CEnology. A. Lonvaud-Funel et al. (eds.), pp. 376-379. Lavoisier Tec \& Doc, Paris.

Schmarr, H.G., S. Ganss, W. Sang, and T. Potouridis. 2007. Analysis of 2-aminoacetophenone in wine using a stable isotope dilution assay and multidimensional gas chromatography-mass spectrometry. J. Chromatogr. 1150(1-2):78-84.

Schneider, V. 2013a. UTA-ein weltweites Problem. Der Winzer 7:24-28.

Schneider, V. 2013b. Bedeutung von Sauerstoff für die Bildung von UTA. Winzer-Zeitung 11:32-33.

Schneider, V., and M. Almeida. 2005. O envelhecimento atípico dos vinhos brancos. Enologia 45,46:25-29.

Schwab, A., M. Peternel, H.J. Köhler, and K.P. Heigel. 1996. Die "Untypische Alterungsnote" in Wein, Teil IV: Beeinflussung durch weinbauliche Massnahmen. Rebe Wein 6:181-187.

Schwab, A.L., and M. Peternel. 1997. Investigation about the influence of a long term green cover on must and wine quality with special consideration of Franconian pedological and climatic conditions. Vitic. Enol. Sci. 52(1):20-26.

Schwab, A.L., N. Christoph, H.J. Köhler, M. Gessner, and T.J. Simat. 1999. Influence of viticultural treatments on the formation of the untypical aging off-flavour in white wines. Vitic. Enol. Sci. 54(4):114-120.

Seiter, P. 2000. Der Einfluss von Stickstoffdüngung und Bodenpflege auf die Stickstoffversorgung der Rebe und die Weinqualität. Eine Studie zum Probem des "Untypischen Alterungstons." Thesis, University of Freiburg, Germany.

Simat, T.J., K. Hoenicke, M. Gessner, and N. Christoph. 2004. Metabolism of tryptophan and indole-3-acetic acid formation during vinification and its influence on the formation of 2-aminoacetophenone. Mitt. Klosterneuburg 54:43-55.

Sponholz, R., T. Hühn, A. Engelmann, and A. Siben. 1997. Possible influence of some viticultural parameters on the incidence of the "untypical" off-flavours in Riesling wines. Vitic. Enol. Sci. 52(1):41-50.

Sponholz, W.R., and T. Hühn. 2001. Untypischer Alterungston. Deut. Weinbau 10:82-87.

Steinhart, H., M. Gessner, H.J. Köhler, and A. Schwab. 2001. Mögliche Entstehung einer untypischen Alterungsnote (UTA) im Wein. GIT Labor-Fachzeitschrift 9:945-948.

Wohlfahrt, P. 1993. Untypische Alterungsnote: Ansätze zur Problemlösung. Badischer Winzer 18(8):318-319.

Zapušek, M. 2007. Atypical ageing off-flavour of white wines. Thesis, University of Ljubljana, Slovenia. 